Andersen, L, and Fyhn, H. (2019): 'Organizational and Cultural Preconditions for Extending the Use of TaktTime Planning.' In: Proc. 27th Annual Conference of the International. Group for Lean Construction (IGLC), Pasquire C. and Hamzeh F.R. (ed.), Dublin, Ireland, pp. 467-476. DOI: https://doi.org/10.24928/2019/0271. Available at: <www.iglc.net>.

\title{
ORGANISATIONAL AND CULTURAL PRECONDITIONS FOR EXTENDING THE USE OF TAKT-TIME PLANNING
}

\author{
Lars Andersen ${ }^{1}$ and Håkon Fyhn ${ }^{2}$
}

\begin{abstract}
This paper presents findings of a study about how to extend the use of Takt-time planning in construction projects. The study is based on analysis of two construction projects involving non-repetitive work that, after failing to use Takt-time planning, had to return to ordinary methods of production. To uncover causes to the problems, the research method Theory-building process tracing is used. Results show that extended use of Takt-time planning presupposes effective coordination in the projecting process and a proactive and well organised production control in the construction phase. It also presupposes high involvement of the craftsmen and crew-leaders in the Takt-time planning and production. The method of theory-building process tracing is transferred from political science and historical studies to construction projects. The research method offers a unit of hypothesis testing and cumulative practical theory development, which can be of general value for construction research. Although the validation of the present empirical results is thorough, based on interviews and workshops, the researchers own observations of the processes studied could have been more extensive.
\end{abstract}

\section{KEYWORDS}

Process tracing, takt-time planning, production control, culture, rationalism

\section{INTRODUCTION}

This paper reports the case studies of two construction projects involving non-repetitive work that failed to use Takt-time planning (TTP) and, as a result, had to revert to ordinary methods of production during the production phase of the projects. The two construction projects examined were organised by the same turnkey contractor who practises a variant of the Last Planner System (LPS) known as the Material Systemic approach (MSa), which was partly used in combination with TTP during the projects. One of the projects used integrated concurrent engineering (ICE) in the design and engineering process, whereas the other used a traditional sequential approach. Since both TTP (e.g., Frandson et al., 2014) and MSa (Andersen, 2018) are presented in previous papers, the following graphs only briefly describe the two methods.

${ }^{1}$ Lars Andersen. Research professor. NTNU - Norwegian University of Science and Technology.

Trondheim. Norway. +047 92885305. Lars.Andersen@samfunn.ntnu.no

${ }^{2}$ Håkon Fyhn. Co-author. Senior researcher. NTNU - Norwegian University of Science and Technology. Trondheim. Norway. +04791743561. 
TP is a method for work structuring and flow (Frandson et al., 2014) that integrates the concept of the assembly line rooted in the manufacturing industry (e.g., Fordism and Toyotism) into construction processes. According to Dlouhy et al. (2018), TTP begins by dividing the object of the project (e.g., a building) into control areas (e.g., rooms or parts of floors) in order for production and the various trades involved to appropriately move forward from one control area to the next. The progression of trades through control areas can be conceived as a train with one trade in each wagon that stops in each control area for the given TTP period (e.g., one week). With tight coupling up of standardized tasks internally and between the control areas, the work structure enables flow with no idle time. The internal production control of TTP follows the logic of planned-percent-done in the LPS; however, the LPS places greater emphasis on proactive production control based on plans that are first detailed near execution and with obstacle analysis making the activities ready (sound) before execution.

In MSa, planning persists throughout construction as an interpretative process that progresses along the dimensions from unclear to clearer and from the abstract to more concrete. In that sense, planning does not stop before execution, as in rationalist planning theory, but continues, e.g., as the cognitive activity of craftsmen as part of their work and as new levels of interpretation are realised through object creation or materialisation (e.g., completing a part of a building). The planning process involves 'division of labour in time' and a reversed meeting structure. The crew or craftsmen make a joint work plan for each week (in the meeting of craftsmen), and crew leaders have similar responsibilities for planning activities 2 or 3 weeks before the activities are initiated (in a meeting of crew leaders immediately after the meeting of craftsmen). Next, middle managers assume responsibilities 4-8 weeks before the activities in question are initiated and meet after the crew leaders' meeting. A management team operates in the timeframe 9 weeks before the progressive production front and onwards. In that structure, plans made ahead of time are continually reinterpreted in light of object creation in the physical building process. This organizational structure, in addition to the actual plan development, also provides a basis for an organized, expanded, proactive production control.

The issue of this paper is: what are the underlying causes that inhibit extended use of TTP in construction processes. The empirical research questions are: 1) What are the immediate causes of the failure of TTP/Tack production in these cases? 2) What are the underlying causes of the failure, if any? 3) What guidelines does the analysis introduce for future extended use of TTP in building projects?

\section{THEORY}

The traditional theory of project management and planning is based on classical rationalism and ideal rationality (Koskela and Howell, 2002) and the over-confident belief in the possibility of realising maximum rationality. According to Simon (1957), maximum rationality is impossible due to restrictions of human recognition and an inherent element of unpredictability in all processes. Instead of aiming at maximum rationality, one must adapt to a limited ability to predict outcomes and reach for satisfactory solutions in a bounded rationality.

TTP and Tack production (in accordance with the Toyota system) exhibit features of classic rationalism insofar as most of the production system is predefined; the individual 
subjects, groups, and activities are preconditioned to operate within long, fixed chains of activities forward in time based on tight links between subjects and tasks. However, TTP also has features of modified rationalism through its emphasis on internal production control. In contrast, LPS can be understood to be grounded in modified rationalism as a planning and control system in which one can flexibly make rapid, extensive changes to the plan for single subjects and groups, operations, and the entire production front in light of altered conditions of production and an unpredictable external empirical reality.

By contrast, MSa thematises the outer empirical world influenced by complexity philosophy and the philosophy of objects (Kärrholm, 2014; Andersen, 2018). In a construction processes, and in light of this approach, the empirical outer reality emerges as meaning-based objects in a double sense of the term: first as materiality by virtue of physical building and second as ongoing differentiations and concretions mediated by the human subjects' perceptions of the outer world.

\section{EMPIRICAL DATA AND METHOD}

The empirical data of the study is based on case studies: Case 1 is a building connected to a sport hall, and Case 2 a mid-sized hospital. The empirical study of Case 1 took place during 8 months in 2018 (in the construction phase). Craftsmen, crew-leaders, foremen, work-manager and site-manager were interviewed in semi-structured qualitative interviews (10 informants) as part of mid, and endpoints evaluations of the project. The study of Case 2 was carried out in two parts: first, 7 months in 2017 (projecting phase), and then 5 months in 2018 (construction phase). The projecting phase was examined by participatory observations of ICE sessions followed up by interviews of architect, coordinator of technical subjects, projecting manager, work manager, site manager and project manager (6 informants). The last three were also interviewed about the production phase. In both cases, studies of the construction phase involved participatory observations in meetings of crew leaders and managers. The researchers were also engaged in weekly on-site inspections with crew leaders with subsequent debriefing with key informants. The data were validated in initial, mid, and endpoint project workshops on site during the observation period. After the observation period additional workshops were arranged with the craftsmen, and with project managers and regional managers of the contractor, during which the results were discussed and further validated.

The study uses the theory-guided process tracing method (Falleti, 2016). The theorybuilding process tracing method requires a process outcome for which there is no obvious cause. The researcher starts out from a defined beginning point of the process and then describes a causal stepwise diagram based on the methods/activities that the actors of the process actually have chosen (or events that has happened) and that may have affected the end-result. The researcher then performs a closer analysis of the empirical outcome of the process and traces its causes backwards in the process by help of theory. The structure of the analyses of the causes is first to describe the method used, then to ask why and how it caused the outcome (the problem). The identification of the factual cause of the problem proves to presuppose the identification of the solution as a counterfactual action - that is, what the actors should have done to realize their intentions. 


\section{RESULTS}

The figure below presents a causal diagram based on steps in the construction process of the two cases. The study is a theory-building process tracing. According to this, the causal diagram moves forward from pre-projecting to the outcome-the building process. The tracing moves backwards from, e.g., an unwished outcome, to prior and underlying causes. Case 1 (building the sports hall) chose to organize the projecting phase the traditional way but used TTP in the construction. Case 2 (hospital) chose lean tools more consistently with ICE in projecting and TTP in construction. Both cases had lean philosophy as a theoretical foundation. The causal diagram of the cases is illustrated below.

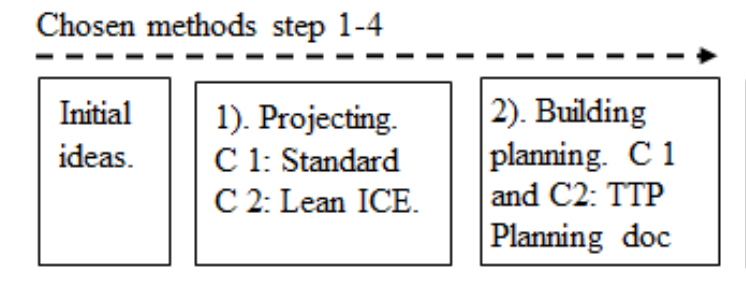

Case $=$ C. Analytical unit step 1: drawings-models. 2: planning doc., 3-4: drawing, models, and planning doc
Step 0). Theoretical foundation: Lean - (MSa)

\begin{tabular}{|l|l|l|}
\hline $\begin{array}{ll}\text { 3). Transfer } \\
\text { phase. C1 } \\
\text { and C : } \\
\text { Latency }\end{array}$ & $\begin{array}{l}\text { 4). Building. } \\
\text { Takt production. } \\
\text { C1-C2: Standar- } \\
\text { dized work. }\end{array}$ \\
\hline
\end{tabular}

Backward process tracing: Unknown causes/reasons to outcome

Diagram 1. Causal diagram. Building project. Theory-building process tracing

\section{CASE 1. PROCESS TRACING (BACKWARD)}

The construction project (building connected to a sports hall) was based on an ordinary turnkey contract using TTP in the building phase.

\section{Outcome: uncontrolled materializations_immediate causes}

Typical signals of problems in Takt production were increased amounts of unfinished tasks in the control areas, an increase in disorder relating to equipment, tools, and materials left behind, and increased traffic of craftsmen between control areas to finish the work. It was especially the carpenters that had problems which caused chain-reactions to the other subjects.

Early in the building process, it was discovered that the Takt schedule was based on relative understaffing of carpenters and that the plans did not sufficiently differentiate between the (non-repetitive) control areas. Use of buffers and corrective measures was not sufficient to relieve the situation. Delayed builder's decisions and changes contributed to unfinished design/engineering and uncertainties regarding the purchase of materials. Due to the resulting lack of production control, the production managers ended up 'firefighting' immediate problems. The production actors interpreted the situation as primarily caused by three external events that garnered attention: one was an unforeseen political process concerning the financing of the building, whereas the other two were ongoing arrangements that took place in the sports hall and the development of outdoor space for the hall; in both, the client was directly involved.

\section{UNDERLYING CAUSES}


Step 4. Building. Chosen method: Takt production. According to TTP/Takt production, the work process is defined in detail before execution. In this case, however, the descriptions of the control areas were imprecise, and the plan included too few carpenters. The carpenters attempted to compensate for this by giving priority to tasks with critical dependencies on other subjects, but this led to their own work being not very rational, which escalated the effects of their own understaffing. The project's available buffers and corrective measures were insufficient to maintain the Takt in production.

Material objects consist of structuring materials that give them unity and stability in space and time. The structuring material in buildings comprise, e.g., concrete, wood, and steel for building floors, walls, ceilings, shafts, etc. (the skeleton of the construction). The form of structuring materials creates a foundation for the other individual installations (e.g., light, ventilation) and how they are placed and work together. This gives the structuring subject (e.g., the carpenter) an opportunity to have a practical coordinating role in the construction process and to develop a corresponding coordination competence.

Counterfactuals: In this case, the carpenters' main crew leader had good 'structuring' competence and interacted with the other crew leaders to carry out improvisations to continually develop and implement corrective actions to 'rescue' the Takt production system once the problems arose. This helped expand the life of the Takt system for a certain period of time.

Step 3. Transfer of documents. Chosen method: latency. The transfer phase is the period after the drawings, models, and planning documents are completed and moved through the planning time windows until they are finally used as a basis for the sequential physical building production on site. The operative planning was formally organized according to the principles of MSa (described initially). However, the meetings further ahead on the time axis than the CL-meeting were at a low level of activity. The transfer of drawings, models, and documents instead took the character of passive transport or latency. This occurred at the same time as the three process-exogenous factors (political processes, arrangements in the sports hall, and outdoor space for the hall) contributed to significant disturbances in the Takt production (delayed builder's decisions and changes that resulted in unfinished engineering and uncertainties regarding the purchase of materials). Normally, measures aimed at major changes in project-external production conditions need to be planned and implemented in due time in order not to disturb the production (e.g., active planning development about week three and forward in time before production). If such changes are not recognized early enough, then possibilities for production control are lost. The lack of proactive and well-organized production control appears to be the main reasons for the collapse of the Takt production in this case. Counterfactuals: The closer the links are between the activities and the more perfect transitions in the Takt productions system, the more vulnerable the system is to any type of variation that affects the production conditions. The need for increased effective proactive production-control increases when variation in exogenous production conditions increases. When practicing TTP/Takt production, one must simultaneously implement, e.g., MSa (or LPS) so that drawings, models, and planning documents are further developed throughout the transfer process. 
Steps 2 and 1. Building planning and projecting. Chosen methods: TTP and traditional projecting. In this project, the projecting and development of TTP followed sequentially. Counterfactuals: The integration of TTP and project planning (cf., Frandzen et al., 2014) could have pushed for increased precision and coordination of projection and construction plans. This effect could be enhanced by the use of structured ICE in the design (see counterfactuals step 1, Case 2).

Step 0. Culture. 'Chosen method' (implicit assumption): lean and rationalism.

Data from the case suggest that the project managers were overconfident in their understanding of the TTP/Takt production system as a self-sufficient system for work structuring and flow. Such an 'implicit assumption' explains why these actors may tend to underestimate the need to combine Takt production with proactive production control. Counterfactuals: When implicit theoretical assumptions are made explicit, they appear as a choice.

\section{CASE 2. PROCESS TRACING (BACKWARD)}

The hospital project was based on a turnkey contract involving interaction between the contractor and the projecting team in the pre-project phase and further in the detailed design phase.

\section{Outcome: uncontrolled materializations, immediate causes}

The immediate causes of breakdown in the Takt production system in Case 2 had many of the same features as in Case 1, but the order of cause was different. The informants reported that the problems were related to uncertainty and failure related to the procurement of materials. However, the informants believed that the problems had largely originated in the design: generally, the level of detail was too low. The informants also reported that the flow in the building process was obstructed by walls not being adequately designed, creating immediate problems for the work on piping and drainage and in a chain reaction for other tasks. While the problems with structuring materials were an underlying cause in Case 1, the walls as structuring material were an immediate cause of the problems in Case 2.

\section{UNDERLYING CAUSES}

Step 4. Building. Chosen method: Takt production. This case used parts of the recipe for TTP/Takt production as in Case 1. Lack of drawings of walls triggers chain reactions among the structuring subjects with the starting point in the carpenter subject. In this case, however, there was no carpenter crew leader (as in Case 1) entering the multidisciplinary coordinating role between the subjects to create an extra buffer in the Takt production. Instead, the problems with Takt production escalated quickly in this case and led to a quick abandonment of the production method.

Counterfactuals. The alternative is (like in Case 1) to develop a 'structured high involvement production system' (cf., the Toyota system) with continuous development of working standards and with the capability to utilize all available forms of buffers against deviations from expected production conditions. Creative interaction between the 
craftsmen crews may have mitigated some of the effects stemming from imperfect drawings, models, and planning documents.

Step 3. Transfer of documents. Chosen method: Latency. During the construction process, there were weekly crew leader meetings for all subjects at which the joint production front for the following 1-3 weeks was to be planned. However, those meetings dealt to a limited extent with the second and third week before the production front. The production control further forward in time was also deficient. Counterfactuals: The situation is the same as in Case 1 . If the MSa had been more consistently practised in the construction phase in Case 2, then obstacles to 'sound' production could have been uncovered earlier and better controlled.

Step 2. Building planning. Chosen method: TTP. TTP was made after and uncoupled from the projecting process. Counterfactuals: Integration of projection and development of the building plan will contribute to increased precision in the object definitions used for projecting.

Step 1. Projecting. Chosen method: ICE. The Case used weekly joint ICE meetings with the planning technique 'wallboard and notes', needs-driven special meetings with smaller interdisciplinary teams, self-directed informal processes between the designers, and management of objectives (cf., the engineer-projecting manager of the turnkey contractor).

The ICE meetings had a clear focus on the status of the progress of the projection and on planned actions and deliveries for the subsequent weeks, however, this left a vacuum regarding interdisciplinary processes. The informants (especially architects and design engineers) reported that the lean tools in use did not reveal the 'undergrowth' of interdisciplinary dependencies in the design, and they called for specialized professional competence to comprehend the complexity of the process. Let's take a closer look at the underlying causes of these experiences.

The overview of immediate causes identified the unfinished design of walls as part of structuring material as a main cause of the failure in production. The analyses (Cases 1 and 2) uncovered how the work of operative building-subjects (e.g., carpenters, carpenters' crew-leader, work manager, etc.) carries in it a special competence for coordinating other subjects. This is grounded in that structuring material also means to structure and give order to the specific material with technological end-effects originating from the other subjects in the building process. When we move the focus back to the design and takes the architect's position and perspective, we look accordingly: in the projecting process, the architect uses his or her own expertise and competence in the modelling of structuring material to coordinate and give meaningful order to the individual user functions ('good light here', 'fresh air', etc.). The individual user functions correspond with individual subjects' deliveries towards the modelling of structuring material. This means that the architect's expertise in coordinating individual user functions also means a special access to competence in order to coordinate other design subjects. 


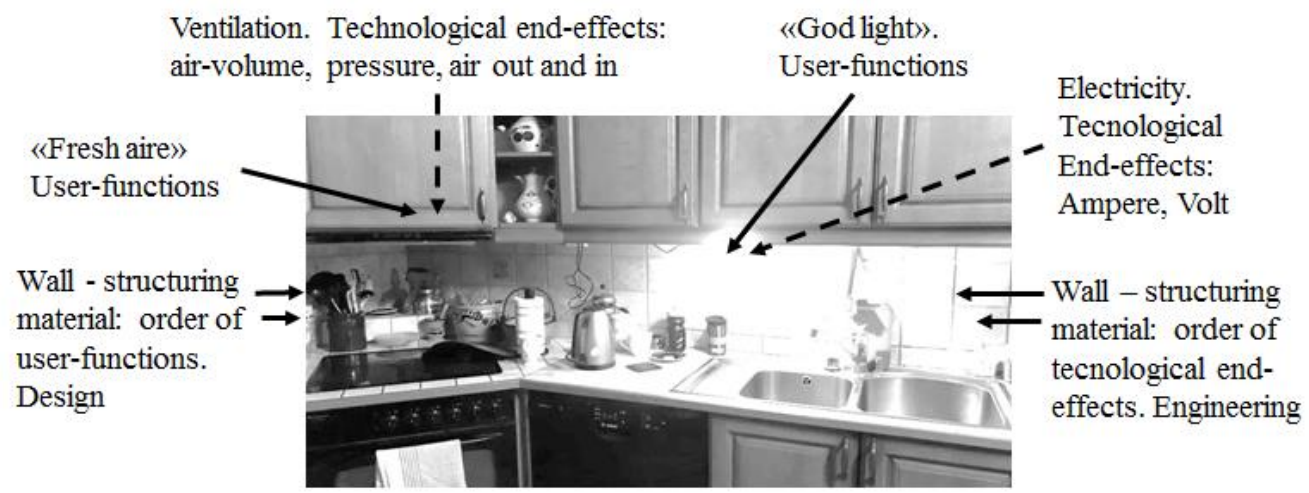

Figure 1. Dimmensions of the building object. Structuring materiel - user functions and end-effects

The practice of ICE highlights the need to develop and integrate the competence and coordination system in projecting with the corresponding system in building execution into one coordination system. The loss of such an integrated coordination system based on structuring material in the projecting phase is, according to our process tracing, a main underlying cause of the failure in the Tact production in the case-project studied.

Counterfactuals. The integrated coordination system is developed through dialogues. The points below outline the actual dialogue and coordination system.

1. The main dialogue and coordination is between the structuring subject axis (architect and operative building subject) and the technical subjects (design engineer and technical engineer subjects) (cf., the main interface of the coordination). See Figure 2.

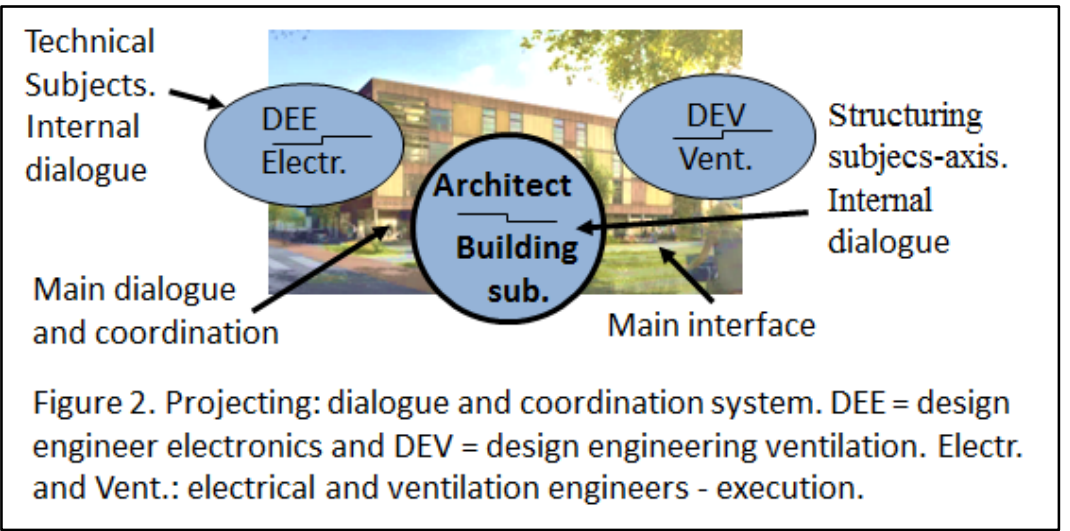

When dialogues and iterations (reciprocal) do not lead to adherence to joint action proposals, the structuring subjects together make decisions - optionally in collaboration with the builder/client.

2. Necessary additional dialogues: a) the structuring subject-axis' internal dialogue (between architect and operative building subject), b) internal technical subjects' dialogues (e.g. between design engineer electronics and electrician engineer subject), c) dialogues design engineering subjects, and d) dialogues between executing subjects.

Related to the case studied, this model of dialogues and coordination will have the 
following consequences: The actors in structuring the subject-axis must (e.g., in ICE meetings) go ahead and develop the plan of their own subject as a decision-making premise for other subjects in the common planning process. The structuring subject-axis will have the coordinator role in the fixed-theme groups. In special meetings and informal communications, the structuring subject-axis would also have the role as coordinating actor between the subjects. In all these situations, the structuring axis has decision-making authority in the main interface of the process. The developed counterfactual dialogue and coordination system provides a formalized, self-directed, expert system of communication and decision making. Management by objectives will in this coordination system have a complementary role with responsibility for progress in decision making etc.

Step 0. Culture. 'Chosen method' (implicit assumption): lean - rationalism. As in Case 1 , management in Case 2 had high confidence in the TTP/Takt production system as a selfsufficient system. The informants highlighted the tendency of the project to 'fall asleep', that is, subjects conceived the schedules and descriptions to be finished and to be followed slavishly. The same trend has been revealed in other studies (Fyhn and Søraa, 2017). The understanding of the process as static appears to be an underlying cause, an unrecognised assumption and preconception originating from the planning optimism of classic rationalistic thinking and culture.

Counterfactuals. The interpretative and open process thinking of MSa stands out as an alternative theoretical foundation of Takt principles. Diagram 2 below shows the counterfactuals developed for each step analysed in the two cases.

New methods step 1-4.
\begin{tabular}{|l|l|l|l|l|l|l|}
\hline $\begin{array}{ll}\text { Initial } \\
\text { ideas. }\end{array}$ & $\begin{array}{l}\text { 1) Projecting. } \\
\text { Self directed expert } \\
\text { coordination. Struc- } \\
\text { turing subject-axis. }\end{array}$ & $\begin{array}{l}\text { 2). Building } \\
\text { planning. } \\
\text { Integration } \\
\text { Drawings-TTP }\end{array}$ & $\begin{array}{l}\text { 3). Transfer } \\
\text { phase. Proactive } \\
\text { produc. controll. } \\
\text { MSa organizing }\end{array}$ & $\begin{array}{l}\text { 4. Building, TTP } \\
\text { and Structured } \\
\text { high involvment } \\
\text { production system. }\end{array}$ & $\begin{array}{l}\text { Outcome. } \\
\text { Controlled } \\
\text { materiali- } \\
\text { sations }\end{array}$ \\
\hline
\end{tabular}

Step 0). Theoretical foundations: Emergence and interpretative method - MSa

Diagram 2. Building project. Methodes based on counterfactuals

\section{DISCUSSION}

When using the theory-building process tracing research method, causes to problems are revealed and counterfactuals developed using theory, which is then tested in the next project. The backward process tracing in this study gave the following results: Step 1: The counterfactual 'expert-driven, self-directed, dialogical coordination system' presupposes object philosophy and allows one to understand the limitations in ICE caused by unstructured reciprocal social relations between actors. Step 2: 'Radical integration of the making of the building plan with projection (and procurement)' presupposes self-directed projecting and can uncover the weaknesses in sequenced projection and the making of the building plan. Step 3: The counterfactual 'increased proactive production control', based on continuous further development of the drawings and plans and on extended organization 
in the transfer phase, provides a deeper understanding of the problems with latency of the documents in the same phase. Step 4: The identification of the solution 'structured highinvolvement production system' makes it possible to understand how standardized work may contribute to uncontrolled materializations. Step 0: The alternative theoretical foundation based on interpretative object-philosophy and open process understanding is used in the causal analyses and to develop individual counterfactuals. The theoretical foundation itself is also further developed through stepwise analysis in the process tracing.

It is known that in LPS, plans and purchasing (and projecting?) must be detailed close to the execution of activities. In contrast, the rationale in TTP assumes detailed plans, predefined activities, and that procurement is decided early in the process. The counterfactuals presented in this paper may contribute to making TTP more resilient. A further possible solution to the paradox of the early detailing of plans and the opposite need for flexibility here and now may be to divide the building projects into many smaller phases and postpone the details (projecting, design of the Takt plan, and procurement) until the individual phase is to be performed.

\section{REFERENCES}

Andersen, L. (2018): Complexity and rationality: a material-systemic approach. https://www.emeraldinsight.com/doi/full/10.1108/IJMPB-10-2017-0116

Dlouhy et al. (2018): Mastering complexity in Takt planning and Takt control - using the three-level model to increase efficiency and performance in construction projects. IGLC 2018. Chennai India. 1365-1374.

Falleti, T.G. (2016): Process tracing of extensive and intensive processes. New Political Economy. 21:5, 455-462. Routledge, Taylor and Francis Group.

Frandson A.G. et al. (2014): Takt-time planning and the Last Planner. Proceedings. IGLC. Oslo, Norway.

Fyhn, H. and Søraa, R.A. (2017): Craftsmanship in the machine: sustainability through new roles in building craft at the technologized building site. Nordic Journal of Science and Technology Studies 2017 Vol. 5 (2) s. 71-84.

Kärrholm, M. (2014): Interobjectivity in architectural research and theory: towards a metatheory of materiality and the effects of architecture and everyday life. The Journal of Architecture. Taylor \& Francis Group. London.

Koskela. L. and Howell, G. (2002): The underlying theory of project management is obsolete. Project Management Institute.

Simon, H. A. (1957). Administrative behaviour. Fallköping. Gummessons Boktryckeri. Tommelein, I. (2017): Collaborative Takt Time Planning of non-repetitive work. Proceedings. IGLC. Heraklion, Greece. 